\title{
Is Competency Enough? Understanding Job Performance in an Economic Depression Context
}

\author{
Andreea Ţuţu \\ Department of Psychology, Alexandru I. Cuza University of Iasi, Romania \\ E.mail: andreea.tutu@gmail.com
}

Accepted: January 11, 2012 Published: January 30, 2012

Doi:10.5296/ijld.v2i1.1273 URL: http://dx.doi.org/10.5296/ijld.v2i1.1273

\begin{abstract}
Job performance has received an increased attention in the last decades. Aiming to better understand its determinants from a positive individual-orientated view, this paper's fist objective is to investigate the interacting effect of the employee's job competency and organizational citizenship behaviors on job performance levels of a sample of 200 Romanian employees (participation rate: $86.2 \%$ ). Secondly, this research aims to analyze the interacting effect of employees' organizational citizenship behaviors and of Employer's organizational economic behaviors in a context of global economic depression. We used correlation analysis, prediction models, and, as tools, competency assessment checklists developed by means of the Competency Elicitation Interview (Faix et al., 1991), Robertson's performance scales for job performance (1996, 1997), Smith's scale for organizational citizenship behaviors (1983).

Results support the idea that job performance can be approached from a multidimensional point of view. The significance of organizational citizenship behaviors as translations of personal involvement acts into the organization was successfully established, highlighting the important role they have in relationship with job performance. As valid predictors of supervisory ratings of employees' performance, organizational citizenship behaviors seems to have the most important predictive power with a percent of $55 \%$ of the performance's variance explained. Furthermore, job competencies alone seem to be necessary but not sufficient to predict high levels of job performance (with a predictive power of $10 \%$ ). Surprisingly, the interaction effect of employees' organizational behaviors and organizational economic behaviors of the Employer reveals an unexpected paradox in relationship with individual job performance. Main limitations (such as those who refused to participate they didn't had comparable demographics with those who agreed to participate) along with main findings are being discussed.
\end{abstract}

Key Words: job performance, job competency, organizational citizenship behaviors, organizational economic behaviors. 


\section{Introduction}

As literature abounds in definitions, models and methods for the assessment and understanding of the job performance, each author defines job performance in a significantly different manner. The debate regarding the nature of performance reveals two approaches. Some authors see the performance as being results and outcomes, and define it as the history of produced results of a certain determined professional activity or in a certain position (Ainsworth \& Smith, 1993; Bernardin et al., 1995b, apud Robertson, Callinan \& Bartram, 2002, p. 140). From this perspective, global job performance should be the sum (or average) of job outcomes. On the other hand, the most of the authors consider the job performance as the sum of behaviours that employee controls in a certain professional context (Bartram, 2000; Campbell et al., 1993; Robertson, Callinan \& Bartram, 2002), which are crucial for reaching the planned individual outcomes and objectives (Bartram, 2000; 2002; Campbell et al., 1993), and which are relevant for the organizational objectives (Schmitt \& Chan, 1998). If behaviours can be evaluated separately, performance is understood as an interconnected series of behaviours (Robertson, Callinan \& Bartram, 2002). Others (Wu \& Hou, 2010, p. 568) argue that there can be created a performance pyramid model and performance assessment should be performed based on organizational levels, job characteristics and workplace conditions. Viswesvaran \& Ones (1996) argue that the influence of performance determinants is difficult to be estimated and, for most of them, the literature does not provide the percentages of job performance variance explained.

If we agree, as most of the authors, that performance can be understood as an interconnected series of behaviours and actions, then we should take into account both the individual and workplace elements which can influence these actions. The current paper aims at understanding the job performance, defined here as sum of behaviours, by exploring its relationships with job competency, organizational citizenship behaviors and organizational economic behaviors. Job competencies represent abilities to use knowledges, skills, behaviours and personal characteristics in order to sucessfuly perform professional tasks, specific functions or to succesfully fill in a specific role (Ennis, 2008) and ,are causal-related to the efficacy and /or superior performance" (Boyatzis, 1982, p. 23). Other authors extended the competencies definition by adding the motivation to work as importat element which impact the success on a professional activity (Boyatzis, 1982; Falmer \& Conger, 2004; Sandberg, 2000, apud Ennis, 2008). Nevertheless, job competencies are, for some authors, important prerequisites of job performance (Lucia \& Lepsinger, 1999; McClelland, 1973), observable dimensions of performance (Athey \& Orth, 1999) or dispositions toward performance (such as motives, abilities, traits and atitudes) (Brandstatter, 1998) that can partially predict it (van den Berg, 1998). Understood as capacities, skills, knowledge and abilities, competencies are stable in time and can be used in a large range of siuations. In this paper we acknowledge the fact that competencies are necesary in order to be able to perform in a professioal task. However, due to its general definition that can cause sometime confusion (Woodruffe, 1992), we question and we investigate to see if competencies are sufficient in order to predict a high job performance level. 
Due to the distinction between formal and informal aspects required by a position, role or job, the literature promotes the distinction between in-role performance, understood as work performance driven from the formal needs, objectives and aspects of the job, and organizational citizenship behaviors (OCB), or extra-role performance. OCB refers to the informal expectations regarding the employee's behaviors in a professional context and it is defined as sum of extra-role behaviors which contribute to the organizational performance, but which are not formally requested by a certain job description, nor controlled or imposed (e.g.: helping the colleagues, being on time, promoting the organization in a personal or informal context, developing self), and which are complementary to the job formal requirements. Some authors refer to it as contextual performance (Van Dyne et al., 1995), extra-role performance (Tutu, 2011), prosocial organizational behaviors (Brief \& Motowidlo, 1986), or organizational spontaneity (George \& Brief, 1992). Studies have showed that OCB influence the job perfomance (MacKinzie et al., 1991; Nikolaou \& Robertson, 2001; Tutu, 2011), and the management scoring behaviour for global performance. Moreover, some of these studies identifyed a relationship between OCB and the orgaizational efficacy indices.

We refer to organizational economic behaviors of Employer as the sum of crisis induced economic behaviors which affect directly the employees (e.g. of negative organizational economic behaviors: collective lay-offs, technical unemployment, and salary cut-offs). Previous studies showed that the negative organizational economic behaviors have a negative impact on self-perceived job efficacy (Tutu, 2011) and may be responsible, as an additional cause, for the appearance of some psychopathological elements at workplace (Tutu, 2010).

\section{The present study}

The referral literature offers many models of job performance factors. While the traditional approach relates performance and the IQ and personality traits, the current approaches promote the idea that performance is function of individual capacities and motivation. This idea was extended and theorised by Campbell (1993) who proposed a multidimensional model of performance. The declarative knowledge, procedural knowledge and motivation, as choosing behaviours, are the main performance determinats promoted by this model. Taking into account the Campbell's theoretical ideas, our research aims at investigating the influence of job competencies (as concept which also includes individual's knowledge) and organizational citizenship behaviors. Thus, we intend to see if the results suggesting that OCB can predict job performance (MacKinzie et al., 1991; Nikolaou \& Robertson, 1999; Tutu, 2011; Waldman, 1994) would replicate. Our main objective is to first to test the replicability of a prediction model of job performance based on job competency and organizational citizenship behaviors and then to analyse the interaction effect of OCB and organizational economic behaviors of Employer on job performance. In some recent poll responses analysis, The Chartered Institute of Personel ad Development (http://www.cipd.co.uk/) suggested that that rising levels of job insecurity are making it difficult to maintain levels of engagement among employees. Translating the involvement in acts of organizational citizenship, the current study aims at understanding the impact of global 
economic depression operationalised as organizational economic behaviors over the OCB and job performance.

Thus, we have formulated the following hypotheses:

Hypothesis 1: Job competency matching index (calculated as difference between current job competency level and standard required job competency), current job competency levels and organizational citizenship behaviors would positively predict job performance.

Hypothesis 2: Negative organizational economic behaviors of Employer will negatively impact organizational citizenship behaviors of Employees and job performance. Operationally, we intend to test if gender impacts OCB levels, as other studies reported (Nikolaou \& Robertson, 1999) in an organization displaying negative economic behaviors.

Overall, we aimed to investigate if the profile of a good performer can be predicted by the individual aspects (e.g.: job competency and $\mathrm{OCB}$ ) or shaped by the organizational settings (e.g.: organizational economic behaviors).

\section{Method}

\subsection{Sample}

The subjects were employees of seven medium size Romanian based companies. A number of 200 of the total number of the employees were involved in the study (participation rate was $86.2 \%$; 23 employees refused to participate, and other 9 completed the questionnaires in an invalid manner). The mean age is 42.2 years. 90 persons were employed in the in the production sector, in companies forced by the economic depression to operate collective lay-offs, technical unemployment and/or salaries cut-offs between 2009-2011.

\subsection{Procedure}

Letters of invitations were sent to all participants by e-mail. The invitation included a brief study explanation and a description of the associated benefits for participants. There were collected ratings for competencies levels, job performance and OCB (from the management). The research was endorsed by management and the participation was voluntarily. Data were collected personally by the author.

\subsection{Measures}

For competency assessment were have developed ad-hoc checklists, based on the data collected by the Competency Elicitation Interviews (Faix et al., 1991). During special management meetings in each company, the management team collectively defined a checklist with competencies for each position/level in the company. We called it the standard required competency; it contains 12 competencies clustered in three categories (technical, methodological and social competencies), scored on four points bars. Then the management was invited to assess the employees' current competencies. A total score was calculated, resulting an overall job competency level, which was compared with a previous calculated standard required competency level for each position. Based on the differences resulted from these comparisons the job competency matching indices were calculated.

Job performance was assessed using Robertson's Performance Scale. This measure was successfully used in other studies (Robertson et al., 1998, 1999, 2000) as an overall job performance score, eliciting a high internal consistency reliability $(\alpha=.86)$. The scale has 6 items (e.g.: "Achieves the objectives of the job"; "Demonstrates expertise in all aspects of the 
job") and the supervisor indicates whether he /she agrees or not with the behavior described in a five-point scale. Its application is easy, with an average completion time of 10 minutes.

For organizational citizenship behaviors measurement a scale developed by Smith et al. (1983) was used. It consists of 16 items (e.g.: "Helps other employees with their work when they are absent" or "Does not take unnecessary time off work") where supervisors rate their subordinates on a five-point scale. Using factor analysis with varimax and oblimin rotation, the authors identified two dimensions: altruism and generalized compliance or conscientiousness, which had adequate internal consistency. These results were also tested with similar findings in other studies (Organ \& Konovsky, 1989; Becker \& Randall, 1994). For the present study an overall score for OCB was used, along with the specific scores for altruism and generalized compliance scales.

The collected data were statistically analyzed with SPPS 17.0 for Windows.

\section{Results}

Table 1 shows the correlation analysis for testing the relationship between job competency and job performance.

Table 1. Correlation analysis between current job competency, standard job competency and job performance

\begin{tabular}{lllll}
\hline & 1 & 2 & 3 & 4 \\
\hline 1. Current Job Competency Level & 1 & $.570^{* *}$ & $528^{* *}$ & $.464^{* *}$ \\
2. Standard Job Competency Level & $.570^{* *}$ & 1 & $-.396^{* *}$ & $.252^{* *}$ \\
3. Competency Matching Index & $528^{* *}$ & $-.396^{* *}$ & 1 & $.258^{* *}$ \\
4. Job Performance & $.464^{* *}$ & $.252^{* *}$ & $.258^{* *}$ & 1 \\
\hline
\end{tabular}

An expected result was the negative correlation between standard required competency levels and matching competency index $(\mathrm{r}=-.396, \mathrm{p}<.001)$. Job performance correlates positively with current competency levels $(\mathrm{r}=.464, \mathrm{p}<.001)$, standard required competency levels $(\mathrm{r}=.252, \mathrm{p}<.001)$, and with competency matching index $(\mathrm{r}=.258, \mathrm{p}<.001)$. To test the prediction power of these variables four prediction models were run. We have no evidence that that competency matching indices (e.g.: competency matching index, technical competency matching index, methodological competency matching index, social competency matching index) would predict job performance. The current job competency level alone explained 10\% of the job performance variance $(b=.38, t=3.32, p=.001, R$ square $=.10, F=16.34, p<.005)$.

When testing the relationship between OCB and job performance we found a significant positive correlation, $r=.74^{* *}, \mathrm{p}<0.01$. This fact translates that the employees who display organizational citizenship behaviors (e.g.: helping their colleagues, being punctual, taking initiatve) are likely to obtain higher job performance scores when being evaluated by their supervisors. For testing OCB prediction power regression analysis was used. Data showed that OCB significantly predicts job performance scores $(b=.74, t=7.05, p<0.01)$, by explaining a $55 \%$ percentage of variance of job performance scores $(\mathrm{R}$ square $=.55, \mathrm{~F}=$ 129.33, $\mathrm{p}<0.01)$. However, OCB together with current job competency had a significantly lower predictive power (Table 2). 
Table 2. Hierarchical regression models

\begin{tabular}{llr}
\hline Predictor(s) of the regression model & $\begin{array}{l}\text { Percentage of job } \\
\text { performance } \\
\text { explained }\end{array}$ & \\
\hline 1. Competency matching index & $0 \%$ \\
2. Current job competency & $10 \%$ \\
6. Extra-role performance & $55 \%$ \\
7. OCB + competency matching index & $35 \%$ \\
\hline
\end{tabular}

Exploring the descriptive statistics for the second hypothesis, we found a negative effect of organizational negative economic behaviors on job performance $(r=-371, p<0.05)$. However, for organizational citiznship behaviors we found a pardoxal result, with employees from a production context displaying higher levels of OCB in the presence of some negative economic begaviors (as colective lay-offs and salaris cut-offs). Results suggest (see Table 3) that the employees who are working in the production field, hardly affected by the global economic depression, tend to display significantly more helping, volunteering and proactive behaviors. As these results contradicted a previous study (Tutu, 2011), we further analysed the altruism subscale score relationship with the negative organizational economic behaviors. Results suggest that the altruism level seems to be higher at the employees affected by negative organizational behaviors induces by the global financial crisis.

Table 3. Employees' OCB means differences

\begin{tabular}{lllll}
\hline Variable & & $M$ & $t$ & $p$ \\
Environment & production & 3.66 & $-3.37 * *$ & .001 \\
& other & 4.01 & & \\
\hline
\end{tabular}

To see if the results are generated by the particularities of our production sample, and having in mind that OCB has a 55\% predictive power on the overall sample, we tested once again the relationship between the negative organizational economic behaviors and the job performance. Particularly on these employees we found that OCB level is higher in the presence of negative economic behaviors of Employer, and the OCB maintains its positive impact on job performance. For the employees from the other companies involved in the study, which displayed few or no negative organizational economic behaviors, data suggested that the altruism level was lower.

Operationally, for the overall sample, we found no evidence to support the results from other studies (Nikolaou \& Robertson, 1999) that gender will determine significant differences in OCB levels displayed $(\mathrm{Mm}=3.86$; $\mathrm{Mf}=3.82)$. Surprinsingly, when analyzing the OCB levels taking into account the gender and the type of the company, some evidence were found suggesting that women employed in the production environment tend to display more organizational citizenship behaviors than the women employed in the other fieds ( $\mathrm{Mfp}=4.15$ Mfo $=3.81$ ).

\section{Discussion}

The present study investigated the impact of job competency, organizational citizenship behaviors and organizational economic behaviors induced by the global economic depression in relationship with employees' job performance. This paper examined research 
findings from Romania, an Eastern European country and a member of the European Union, where none of these research questions have been explored systematically before.

The results of the current study highlight the importance of OCB, understood as contextual behavior, and of current job competency in work settings and more specifically in performance assessment and performance management, confirming that they are valid predictors of supervisory ratings of employees' performance. The hypothesis that job performance would be affected by job competency matching index was not supported. The results suggest that competency matching index alone is not a valid predictor. Only organizational citizenship behaviors were important positive predictors of ratings of job performance and also they explained variance in job performance above and beyond the effect of competencies (job competency matching index has no prediction power, current job competency seems to explain a percentage of $10 \%$ of job performance variance while OCB seems to have a higher predictive power $-55 \%$ ).

Prior research (Mackenzie et al., 1991; Lowery \& Krilowicz, 1996; Nikolaou \& Robertson, 1999; Tutu, 2011) has provided evidence that OCB influence the supervisor's ratings when evaluating employees' job performance. The results of the present study replicated the previous findings, contextual behaviors proving to be a valid and powerfull predictor of job performance. Some authors (Organ, 1988; Lowery \& Krilowicz, 1996) suggested that one reason that extra-role behaviors influence the job performance evaluations could be that these behaviors actualy contribute to organizational performance. Another valid reason could be that managers may have preconceived concept of what a good performer do, and extra-role performance may be part of this concept. In the present study it seems that engaging in organizatioal citizenship behaiours is seen as an important aspect of job performance for managers, sometimes more important than job competencies in the overall assessment.

Moreover, in the production sector, due to the economic impact og global crisis, translated into negative organizational economic behaviors, employees seems to have a paradoxal reaction, namely they seem to manifest more altruistic behaviors towards colleagues, than the employees from companies which didn't operated collective lay-offs, or salaries cuts.

As far as gender difference is concerned, the present study found no evidence in the overall sample that gender would influence OCB, as previous studies suggested (Nikolaou \& Robertson, 1999). These current results support recent suggestions that no gender difference exists in management ratings of job performance (Arvey \& Murphy, 1998). However, when the statistical formulas were run on the production sample, we found some small gender differences suggesting that women form production sector end to be more altruistic that the female subject from the other fields.

Even if these results may indicate a positive reaction of employees to the global crisis effects in organizations, we need to pay a special attention recognizing the possible bias on the sample selection (the subjects from the production field involved in this research seem to have some particularities which are not also present in the general sample; we suspect major differences in the socio-demographical variables). Another limitation of this study is that a large part of the measures have originated from the same source (management ratings), a 
contamination from common method variance being possible to appear. Furthermore, those who refused to participate they didn't had comparable demographics with those who agreed to participate $(90 \%$ from the subjects who refused participation were from the production environment), which might indicate also a biased sample problem.

The primary attempt of the present study was to examine the combined effect of OCB and job competency (both competency matching index with a standard required job competency level and current job competency), in the prediction of job performance.

The significance of OCB was successfully established, highliting the important role they have in relationship with job performance. Surprisingly, the matching level between current and required job competencies seems to have no power in predicting job performance. Future research should atempt to explain why this competency matching index seem to have no influence over job performance, while current job competency level alone seems to predict almost $10 \%$ of its variance.

The second objective of this study was to investigate the relationship between OCB levels and the organizational economic behaviors of Employer (induced by the global economic context and crisis). Surprisingly, for the sample of the subjects employed in the production sector, a field hardly affected by the crisis, where organizations had to display significantly more negative ecoomic behaviors (e.g.: salaries cuts-off, colective lay-offs, technical unemployment, so on), we found that altruism levels seems to be higher than in the overall sample. This fact might be a translation of a cohesion group reaction towards the economic context.

As far as the practical implications of this research are concerned, the relationship between job performance, OCB, job competency and organizational economic behaviors is very important both for professionals and for employees. The current recruitment and assessment practices from the Romanian organizational context rely almost exclusively on matching one individual's competencies with some professional competency requirements, ignoring the effect of individual difference. Even if the prediction power of these predictors vary, these findings highlight the importance of organizational citizenship behaviors, supporting the idea that job competencies alone are necesary but not sufficient in order to become a good performer. From a social and individual psychology point of view, these findings could be challenging especially in the context of the economic crisis. Future research settings which would test these resuts are especially important in order to see if the OCB and altruism levels were higher in subjects facing hardships at workplace due to the effects of global economic crisis, as a group and individual reaction of cohesion or, in this case we ca speak about a sample bias. Moreover, precisely in the current current European context, it should be interesting to investigate which are the main causes which could determine employees to be more altruistic in periods of economic challenges.

\section{Acknowledgement}

This paper had appeared due to the financial support obtained through the project POSDRU/88/1.5/S/47646, co-financed from European Social Fund, through Sectorial Operational Program for Human Resources Development 2007-2013. 


\section{References}

Arvey, R.D., \& Murphy, K.R. (1998). Performance evaluation in work settings. Annual Review of Psychology, 49, 141-168.

Athey, T.R., \& Orth, M.S. (1999). Emerging competency methods for the future. Human Resource Management, 38(3), 215-225.

Bartram, D., Kurz, R., \& Bailey, R. (2000). The SHL Competency Framework. Internal SHL Memorandum, March 2000, Thames Ditton: SHL.

Baterman, T.S., \& Organ, D.W. (1983). Job statisfaction and the good soldier: the relationship between affect and employee "citizenship". Academy of Management Journal, 26, 587-595.

Becker, T.E., \& Randall, D.M. (1994). Validation of a measure of organizational citizenship behaviour against an objective behavioural criterion. Educational and Psychological Measurement, 54, 160-167.

Boyatzis, R. E. (1982). The competent manager, New York, Wiley.

Brandstatter, H. (1998). Personliche verhaltens-und leistungbedingungen. In H. Schuler (Ed.), Organisationspsychologie, 213-233, Bern, Hans Huber.

Campbell, J. P., McCloy, R. A., Oppler, S. H., \& Sager, C. E. (1993). A theory of performance. In Schmitt, N., Bormann, W.C. et al. (Eds.), Personnel selection in organizations, 35-70, San Francisco, Jossey-Bass.

Ennis, M. R. (2008). Competency models: a review of the literature and the role of the employment and training administration (ETA), US. Department of Labor.

Faix, W. G., Buchwald, C., \& Wetzler, R. (1991). Skill-management: qualifikations planung fur unternehmen und mitarbeiter, Wiesbaden, Gabler.

Lowery, C.M., \& Krilowicz, T.J. (1996). Effects of organizational citizenship behaviours: evidence from production supervisors. International Journal of Selection and Assessment, 4, 18-23.

Lucia, A., \& Lepsinger, R. (1999). Competency models: pinpointing critical success factors in organizations, San Francisco, Jossey-Bass.

Mackenzie, S.B., Podsakoff, P.M., \& Fetter, R. (1991). Organizational citizenship behaviour and objective productivity as determinants of managerial evaluations of salespersons' performance. Organizational Behavior and Human Decision Processes, 50, 123-150.

McClelland, D. C. (1973). Testing for competence rather than 'intelligence', American Psychologist, 28, 1-14.

Nikolaou, I., \& Robertson, I.T. (1999). The influence of employees' work competencies and contextual behaviour on managers' performance appraisals. In P.G.W. Jansen \& R. Pepermans, (Eds.), Empirical studies of managerial behaviour, development and socialization. (pp. 79-94). Leuven, Belgium: ACCO.

Nikolaou, I., \& Robertson, I.T. (2001). A five-factor model of personality and work behaviour in Greece. European Journal of Work and Organizational Psychology, 10(2), 161-186.

Organ, D.W. (1988a). Organizational citizenship behaviour. Lexington, MA: Lexington Books. 
Organ, D.W. (1988b). A restatement of the satisfaction-performance hypothesis. Journal of Management, 14, 547-557.

Organ, D.W., \& Konovsky, M. (1989). Cognitive versus affective determinants of organizational citizenship behavior. Journal of Applied Psychology, 135, 339-350.

Robertson, I. T., \& Gibbons, P. (1996). Understanding management performance. Paper presented to The British Academy of Management Conference, University of Aston, Birmingham, September 1996.

Robertson, I. T., Baron, H., Gibbos, P., MacIver, R., \& Nyfield, G. (1997). Conscientiousness and job success for manager. Paper presented at the Annual Occupational Psychology Conference, British Psychological Sociey, Blackpool, 1997.

Robertson, I.T., \& Callinan, M. (1998). Personality and work behavior. European Journal of Work and Organizational Psychology, 7, 317-336.

Robertson, I.T., Gibbons, P., Baron, H., MacIver, R., \& Nyfield, G. (1999). Understanding management performance. British Journal of Management, 10, 5-12.

Robertson, I.T., Baron, H., Gibbons, P., MacIver, R., \& Nyfield, G. (2000). Conscientiousness and managerial performance. Journal of Occupational and Organizational Psychology, 73, 171-180.

Robertson, I. T., Callinan, M., \& Bartram, D. (2002), Organizational effectiveness: the role of psychology, Chichester, John Wiley \& Sons, LTD.

Schmitt, N., \& Chan, D. (1998). Personnel selection, Thousand Oaks, London, New Delhi, Sage.

Smith, C.A., Organ, D.W., \& Near, J.P. (1983). Organizational citizenship behaviour: its nature and antecedents. Journal of Applied Psychology, 68, 653-663.

Tutu, A., \& Constantin, T. (2011). Understanding job performance through persistence and job competency. In the Volume of the International Conference "Psychology and the Realities of the Contemporary World”, 27-30 October 2011, Bucharest, Romania.

Tutu, A. (2010). Aspecte psiho-sociale ale manifestarilor depresiv-anxioase n contextul crizei economice. In the Volume of the National Conference of Young Researchers "Dezvoltarea Comunitara si Incluziune Sociala in Perspectiva Socio-Economica", 10-11 December 2010, Iasi, Romania.

Van den Berg, P.T. (1998). Competencies for work domains in business computer science. European Journal of Work and Organizational Psychology, 7(4), 517-531.

Woodruffe, C. (1992). What is meant by a competency?, In Boam, R. and Sparrow, P. (Eds.), Designing and achieving competency, London, McGraw-Hill.

Wu, Y.J., J.L. Hou (2010). An employee performance estimation model for the logistics industry. Decision Support Systems, 48, 568-581. 